\title{
Association of Leisure Time Physical Activity Original Association of Leisure Time Physical Activity Article and Metabolic Syndrome over 40 Years
}

\author{
Mi-Young Park, Sung-Hi Kim*, Yoon-Jeong Cho, Rae-Ho Chung, Ki-Tae Lee
}

Department of Family Medicine, Daegu Catholic University College of Medicine, Daegu, Korea

Background: This study aimed to investigate the relationship between leisure time physical activities (LTPA) and metabolic syndrome (MS).

Methods: Five thousand seven hundred and thirty two adults 40 years old or older were enrolled in the study from April 2009 to December 2010. National Cholesterol Education Program's Adult Treatment Panel III was used for the criteria of MS, and Minnesota Leisure Time Physical Activity Questionnaire was used to measure LTPA. After adjusted covariates (age, hypertension, smoking, drinking, education level, household income level, work time physical activities, and menopause for females), the relationship between LTPA and MS was analyzed using logistic regression analysis.

Results: The prevalence of MS was 22.8\% in men, and 14.1\% in women. Average LTPA was 1,498 kcal/wk in men, and 1,308 $\mathrm{kcal} / \mathrm{wk}$ in women. After adjustment for covariates, the odds ratios of middle and low LTPA compared with high LTPA were 1.06 (0.87-1.34), 1.54 (1.08-1.75), for women, this same association was not seen in men. The prevalence of MS was $22.8 \%$ in men and $14.1 \%$ in women, and their LTPA burned 1,498 and 1,308 kcal/wk, respectively. When the odds ratio of MS for the high LTPA group was set at 1.0, the odds ratio of MS was 1.06 (0.87-1.34) in the middle LTPA group and 1.54 (1.08-1.75) in the low LTPA group in women, which showed that the MS risk increased when the LTPA was lower. This same association was not seen in men.

Conclusion: LTPA was independently associated with metabolic syndrome, but only for women.

Keywords: Physical Activity; Metabolic Syndrome; Health Behavior

\section{INTRODUCTION}

According to the National Health and Nutrition Examination Survey (KNHANES V, 2010), the prevalence of obesity (body mass index, BMI $\geq 25 \mathrm{~kg} / \mathrm{m}^{2}$ ) showed an increase of $25.1 \%$, $31.6 \%, 34.7 \%, 35.3 \%, 35.8 \%$, and $36.3 \% \%$ for men and a slight

Received: August 31, 2012, Accepted: January 9, 2014

${ }^{*}$ Corresponding Author: Sung-Hi Kim

Tel: +82-53-650-4247, Fax: +82-53-650-4122

E-mail:khmksh@cu.ac.kr

Korean Journal of Family Medicine

Copyright (C) 2014 The Korean Academy of Family Medicine

(a) This is an open-access article distributed under the terms of the Creative Commons Attribution Non-Commercial License (http://creativecommons.org/licenses/by-nc/3.0) which permits unrestricted noncommercial use, distribution, and reproduction in any medium, provided the original work is properly cited. decrease of $26.2 \%, 27.4 \%, 27.3 \%, 26.3 \%, 26.0 \%$, and $24.8 \%$ for women in 1998, 2001, 2005, 2007, 2009, and 2010, respectively. However, the rate of moderate to heavy physical activities decreased in both men and women, changing from 33.3\% to $25.4 \%$ and $29.6 \%$ to $22.4 \%$ in 2005 and 2010 , respectively. ${ }^{1)}$ The shortage of physical activity was caused by the automation and industrialization of the modern society and has become a major cause of obesity and metabolic syndrome, and has been highlighted as a global health concern. ${ }^{2)}$ Many study results have revealed that a shortage of physical activity is the actual cause of chronic diseases, and have recommended physical activity to prevent disease. ${ }^{3,4)}$

Metabolic syndrome (MS) refers to a group of disease conditions including hyperinsulinemia, lipid disorders, hypertension, and central obesity, and can be considered the prephase of diabetes and cardiovascular diseases. ${ }^{5)}$ MS is associated with 
the two to threefold rise of cardiovascular disease and the three to fourfold rise of type II diabetes. ${ }^{6}$ Recent epidemiologic studies have reported that moderate to higher intensity physical activities, including leisure time physical activities (LTPA), are effective for the prevention and alleviation of MS. ${ }^{7)}$ A study reported that the increase in physical activity among the study subjects was related to the decrease in MS incidence, ${ }^{8)}$ and other studies reported that increased physical activities reduced the risk factors of MS in the healthy participants. ${ }^{9,10)}$

The guidelines for the prevention of cardiovascular diseases recommends more than 30 minutes of moderate or higher intensity physical activity per day and a low-fat diet (containing less saturated fat and cholesterol). ${ }^{11)}$ Domestic studies also reported an inverse relationship between physical activity and total mortality, ${ }^{12)}$ lipid levels in the blood ${ }^{13)}$ and the risk factors of coronary heart diseases. ${ }^{14)}$ It was shown that patients with chronic diseases such as hypertension, diabetes, hyperlipidemia, or MS had lower physical activity, ${ }^{15)}$ and that the shortage of physical activity contributed to $3.7 \%$ of the health determination factors in South Koreans, independent from obesity. ${ }^{16)}$

In the studies on physical activity, comprehensive physical activities (including occupational tasks or leisure time) are the major concerns of measurement, but work time activities are difficult to measure due to their variety. Therefore, LTPA was used as representative physical activity in the studies or recommendations of physical activity. ${ }^{17)}$ Therefore, this study aimed to investigate the relationship between LTPA and MS in people who visited for a medical check-up.

\section{METHODS}

\section{Study Subjects}

This cross-sectional study was conducted among 6,287 participants (1,980 men and 4,307 women) aged over 40 who visited the health examination center of a university hospital, from September 2006 to December 2012, who agreed to sign the informed-consent for this study. Participants were excluded if they had cardiovascular-related disease ( $\mathrm{n}=532$; stroke, 72 ; myocardial infarction, 139; diabetes, 321) or incomplete answers $(\mathrm{n}=23)$. As a result, a total of 5,732 participants (men, 1,703 and women, 4,029) were included. This study was reviewed and approved by the institutional review board at the Daegu Catholic University Hospital (CR-09-049-RES-04-R).

\section{Method}

1) General characteristics and lifestyle factors

Participants were interviewed about their demographic characteristics and lifestyle using a questionnaire.

2) Study tools

(1) Measurement of leisure time physical activity

The Korean version of the Minnesota Leisure Time Physical Activity Questionnaire was used for LTPA measurements. ${ }^{18)}$ Participants were asked about types, frequency and duration of LTPA (average $\mathrm{h} / \mathrm{d}$, number of $\mathrm{d} / \mathrm{mo}$, number of mo/last year; in the following four categories-walking, doing gymnastics or workouts, engaging in sports, and doing household activities). The kcal burned per week was calculated using the activity metabolic index, which allows the calories burned to be measured using the metabolic equivalent of tasks. The quartiles of LTPA in the men and women were obtained. The first quartile was named 'low LTPA'; the second and third quartiles, 'middle LTPA'; and the fourth quartile, 'high LTPA.'

(2) Physical measurement and blood test

Body mass index (BMI, $\left.\mathrm{kg} / \mathrm{m}^{2}\right)$ was calculated by dividing weight in kilograms by square of height in meter. Waist circumference was measured at the midpoint between the lower margin of the rib cage and the upper margin of the iliac. Blood pressure was measured after at least 5 minutes of rest, using an automatic blood pressure monitor (FT500-R; Jawon Medical, Seoul, Korea), and the mean value was obtained after repeating the measurement. Blood samples were obtained from the brachial vein after at least eight hours of fasting. Fasting blood glucose (FBS) was measured using the hexokinase method, and triglycerides, total cholesterol, and high density lipoprotein (HDL) cholesterol were measured via an enzymatic colorimetric assay

(3) Definition of metabolic syndrome

For the definition of MS, the criteria of the modified National Cholesterol Education Program Adult Treatment Panel 
III (NCEP ATP III, 2007) ${ }^{19)}$ were followed when more than three of the five conditions were met: abdominal obesity (waist circumference: men $\geq 90 \mathrm{~cm}$; women $\geq 80 \mathrm{~cm}$ ); triglycerides $\geq$ $150 \mathrm{mg} / \mathrm{dL}$ or on medication; HDL cholesterol, men $<40 \mathrm{mg} /$ $\mathrm{dL}$, women $<50 \mathrm{mg} / \mathrm{dL}$ or on medication; hypertension, blood pressure $\geq 130 / 85 \mathrm{~mm} \mathrm{Hg}$ or on medication; FBS $\geq 100 \mathrm{mg} / \mathrm{dL}$ or on medication.

\section{(4) Covariates}

Age, smoking (pack years), alcohol intake (g/d), LTPA, education level, household income level, and work time physical activity were included as covariates, as well as menopausal status in women. Pack years were obtained by multiplying average daily packs consumed and years of smoking. Participants were classified into current, past, and non-smoker.

For the assessment of drinking, the monthly drinking rate (based on KNHANES; average alcohol intake more than once/ mo for the last year) was obtained, and participants more than the above range was considered a current drinker; less than the above range despite previous drinking history was considered a past drinker; and never was considered a non-drinker. For work time physical activities, the degree of physical activities at work was evaluated on a scale of 0 to 4 , with 0 referring to no physical activities during work; 1 , office work (mostly sedentary work); 2 , working while standing or walking; 3 , working with some physical labor; and 4, working with vigorous physical labor. Participants with a score of 1 were assigned to low work time activity; those with scores of 2 or 3 , to moderate work time activity; and those with a score of 4 , to high-work time activity. For education level, participants were classified into those with a lower than high school degree (less than 12 years); those with a high school degree or its equivalent (range, 12 to 15 years); and those with a college degree or higher (more than 15 years). For income level, the subjects were classified into those with an average monthly household income of less than one million; 1 to 3 million; and more than 3 million Korean won.

\section{3) Data analysis}

IBM SPSS ver. 19.0 (IBM Co., Armonk, NY, USA) was used for data analysis, and $\mathrm{P}<0.05$ for significance analysis. The analysis was separately performed in men and women. General characteristics and lifestyle including LTPA were compared using linear-by-linear association and analysis of variance. Logistic regression analysis was performed to obtain odds ratio (ORs) and 95\% confidence intervals (CIs) of LTPA with MS, after adjusting for age, socioeconomic factors, lifestyle factors, and menopausal status in women.

\section{RESULTS}

\section{General Characteristics (Men)}

The prevalence of MS was $22.8 \%$ among all 1,703 subjects. The prevalence of MS in low LTPA accounted for $25.5 \%$; middle LTPA, 50.0\%; and high LTPA, 24.5\%. There was no significant difference in MS prevalence according to the level of LTPA: low LTPA was 23.8\%; middle LTPA, 22.0\%; and high LTPA, 23.7\%. The average age of participants increased with the increase in LTPA level: the ages were $52.5 \pm 7.9$ years, $53.4 \pm 8.1$ years, and $55.1 \pm 8.1$ years in low, middle, and high LTPA, respectively. Average energy consumption/wk was $21.8 \pm 38.5 \mathrm{kcal}, 992.6 \pm$ $552.8 \mathrm{kcal}$, and 4,071.1 $\pm 2,032.4 \mathrm{kcal}$, respectively, and the high sensitivity C-reactive protein (hs-CRP) was $0.20 \pm 0.60,0.18 \pm$ 0.53 , and $0.16 \pm 0.40$ in low, middle, and high LTPA, respectively. Low LTPA showed a higher amount of work time physical activities, a lower smoking rate, and a lower education level (Table 1).

\section{General Characteristics (Women)}

The prevalence of MS was $14.1 \%$ among all 4,029 subjects. The prevalence of MS in low LTPA accounted for 25.1\%; middle LTPA, 50.2\%; high LTPA, 24.7\%. MS prevalence decreased with an increase in LTPA: low LTPA accounted for $15.1 \%$; middle LTPA, 14.0\%; and high LTPA, 13.0\%, but was not significant. Average age of participants increased with increasing LTPA level: the ages were $50.7 \pm 7.2$ years, $52.3 \pm 7.0$ years, and $55.1 \pm 8.1$ years in low, middle, and high LTPA, respectively. Average energy consumption/week was $132.9 \pm 101.9 \mathrm{kcal}, 926.5 \pm 428.6 \mathrm{kcal}$, and 3,269.6 $\pm 1,609.6 \mathrm{kcal}$, respectively, and the hs-CRP level was $0.23 \pm 3.12,0.13 \pm 0.37$, and $0.10 \pm 0.24$, in low, middle, and high LTPA, respectively. The low LTPA group showed a higher amount of work time physical activities, a higher smoking rate, and a lower education level (Table 2). 
Table 1. General characteristics of study population of men

\begin{tabular}{|c|c|c|c|c|}
\hline Variable & Low-LPTA $(\mathrm{n}=434)$ & Middle-LTPA $(\mathrm{n}=852)$ & High-LTPA $(\mathrm{n}=417)$ & P-value \\
\hline Age* $^{*}(y)$ & $52.5 \pm 7.9$ & $53.4 \pm 8.1$ & $55.7 \pm 8.1$ & $<0.001$ \\
\hline Leisure time physical activity* (kcal/wk) & $21.8 \pm 38.5$ & $992.6 \pm 552.8$ & $4,071.1 \pm 2,032.4$ & \\
\hline Prevalence of metabolic syndrome ${ }^{\dagger}$ & $103(23.8)$ & $187(22.0)$ & $99(23.7)$ & 0.711 \\
\hline Body mass index $\left(\mathrm{kg} / \mathrm{m}^{2}\right)^{*}$ & $24.0 \pm 2.6$ & $24.1 \pm 2.6$ & $24.2 \pm 2.4$ & 0.560 \\
\hline Waist $(\mathrm{cm})^{*}$ & $86.2 \pm 8.6$ & $85.8 \pm 6.8$ & $85.8 \pm 6.9$ & 0.692 \\
\hline Fasting blood sugar $(\mathrm{mg} / \mathrm{dL})^{*}$ & $93.7 \pm 17.2$ & $94.1 \pm 14.7$ & $96.6 \pm 17.4$ & 0.689 \\
\hline Triglyceride $(\mathrm{mg} / \mathrm{dL})^{*}$ & $153.3 \pm 106.4$ & $147.0 \pm 114.3$ & $141.3 \pm 94.8$ & 0.221 \\
\hline High density lipoprotein cholesterol $(\mathrm{mg} / \mathrm{dL})^{*}$ & $49.2 \pm 11.6$ & $48.6 \pm 10.8$ & $50.1 \pm 11.4$ & 0.087 \\
\hline Systolic blood pressure $(\mathrm{mm} \mathrm{Hg})^{*}$ & $125.0 \pm 14.8$ & $126.2 \pm 14.6$ & $127.7 \pm 14.9$ & 0.024 \\
\hline Diastolic blood pressure $(\mathrm{mm} \mathrm{Hg})^{*}$ & $79.1 \pm 10.8$ & $79.9 \pm 10.8$ & $80.1 \pm 10.4$ & 0.300 \\
\hline High sensitivity C-reactive protein $(\mathrm{mg} / \mathrm{L})^{*}$ & $0.20 \pm 0.60$ & $0.18 \pm 0.53$ & $0.16 \pm 0.4$ & 0.339 \\
\hline \multicolumn{5}{|l|}{ Workact $^{\dagger}$} \\
\hline Lower & $148(34.1)$ & $319(37.4)$ & $189(45.4)$ & $<0.001$ \\
\hline Middle & $154(35.5)$ & $404(47.4)$ & $173(41.5)$ & \\
\hline High & $132(30.4)$ & $129(15.2)$ & $55(13.1)$ & \\
\hline \multicolumn{5}{|l|}{ Smoking status ${ }^{\dagger}$} \\
\hline No & $119(27.4)$ & $261(30.6)$ & $121(29.1)$ & $<0.001$ \\
\hline Past & 144 (33.2) & 334 (39.2) & 203 (48.7) & \\
\hline Current & $171(39.4)$ & $257(30.2)$ & $93(22.2)$ & \\
\hline \multicolumn{5}{|l|}{ Drinking status $^{\dagger}$} \\
\hline No & $104(23.9)$ & $172(20.2)$ & $81(19.3)$ & 0.047 \\
\hline Past & $46(10.6)$ & $67(7.8)$ & $39(9.4)$ & \\
\hline Current & $284(65.5)$ & $613(72.0)$ & $297(71.3)$ & \\
\hline \multicolumn{5}{|l|}{ Education $^{\dagger}(\mathrm{y})$} \\
\hline$\geq 15$ & 99 (22.8) & $282(33.1)$ & 135 (32.4) & $<0.001$ \\
\hline$\geq 12$ to $<15$ & $175(40.4)$ & $360(42.3)$ & $185(44.4)$ & \\
\hline$<12$ & $160(36.8)$ & $210(24.6)$ & $97(23.2)$ & \\
\hline \multicolumn{5}{|l|}{ House income (1,000 won) } \\
\hline$\geq 3,000$ & $163(37.5)$ & $363(42.6)$ & $160(38.7)$ & 0.840 \\
\hline$\geq 1,000$ to $<3,000$ & $206(47.5)$ & $404(47.4)$ & $188(44.8)$ & \\
\hline$<1,000$ & 65 (15.0) & $85(10.0)$ & 69 (16.5) & \\
\hline
\end{tabular}

Values are presented as mean \pm SD or number (\%).

LTPA: leisure-time physical activity, Workact: work time physical activity.

*Analyzed by analysis of variance. ${ }^{\dagger}$ Analyzed by chi-square test (linear-by-linear association).

3. Metabolic Syndrome Prevalence by Age, Leisure Time Physical Activity, and Work Time Physical Activities in Men and Women
MS prevalence showed a rapid increase in women in their 40s, 50 s, and 60s (including 70 years old), but there was no significant change in men. LTPA showed a linear increase with age in men; 
Table 2. General characteristics of study population of women

\begin{tabular}{|c|c|c|c|c|}
\hline Variable & Low-LTPA $(n=1,010)$ & Middle-LTPA $(\mathrm{n}=2,021)$ & High-LTPA $(\mathrm{n}=998)$ & P-value \\
\hline Age* $^{*}(\mathrm{y})$ & $50.78 \pm 7.2$ & $51.8 \pm 7.4$ & $52.3 \pm 7.0$ & $<0.001$ \\
\hline Leisure time physical activity* (kcal/wk) & $132.9 \pm 101.9$ & $926.5 \pm 428.6$ & $3,269.5 \pm 1,609.6$ & \\
\hline Prevalence of metabolic syndrome ${ }^{\dagger}$ & $153(15.1)$ & $283(14.0)$ & $133(13.3)$ & 0.530 \\
\hline Body mass index $\left(\mathrm{kg} / \mathrm{m}^{2}\right)^{*}$ & $23.6 \pm 4.4$ & $23.4 \pm 2.8$ & $23.6 \pm 2.6$ & 0.069 \\
\hline Waist* $(\mathrm{cm})$ & $78.6 \pm 7.6$ & $78.2 \pm 7.5$ & $78.3 \pm 7.6$ & 0.393 \\
\hline Fasting blood sugar (mg/dL)* & $89.1 \pm 20.6$ & $88.7 \pm 14.4$ & $89.6 \pm 15.9$ & 0.094 \\
\hline Triglyceride $(\mathrm{mg} / \mathrm{dL})^{*}$ & $113.4 \pm 72.7$ & $107.8 \pm 67.4$ & $109.6 \pm 83.6$ & 0.170 \\
\hline High density lipoprotein cholesterol (mg/dL)* & $56.4 \pm 12.3$ & $56.1 \pm 11.9$ & $57.2 \pm 13.0$ & 0.067 \\
\hline Systolic blood pressure $(\mathrm{mm} \mathrm{Hg})^{*}$ & $119.5 \pm 14.9$ & $120.8 \pm 14.7$ & $121.7 \pm 15.1$ & 0.009 \\
\hline Diastolic blood pressure $(\mathrm{mm} \mathrm{Hg})^{*}$ & $76.6 \pm 10.0$ & $76.2 \pm 10.3$ & $76.8 \pm 10.7$ & 0.664 \\
\hline High sensitivity C-reactive protein $(\mathrm{mg} / \mathrm{L})^{*}$ & $0.23 \pm 3.12$ & $0.13 \pm 0.37$ & $1.10 \pm 0.24$ & 0.004 \\
\hline \multicolumn{5}{|l|}{ Workact $^{\dagger}$} \\
\hline Lower & $745(73.8)$ & $1,437(71.1)$ & $771(77.1)$ & 0.031 \\
\hline Middle & $203(20.1)$ & $443(21.9)$ & 187 (18.9) & \\
\hline High & $62(6.1)$ & $141(7.0)$ & $40(4.0)$ & \\
\hline \multicolumn{5}{|l|}{ Smoking status $^{\dagger}$} \\
\hline No & $948(93.8)$ & $1,920(95.0)$ & 965 (96.7) & 0.015 \\
\hline Past & $23(2.3)$ & $34(1.7)$ & $14(1.4)$ & \\
\hline Current & $39(3.9)$ & $67(3.3)$ & $19(1.9)$ & \\
\hline \multicolumn{5}{|l|}{ Drinking status $^{\dagger}$} \\
\hline No & $630(62.3)$ & $1,343(66.5)$ & $627(62.8)$ & 0.878 \\
\hline Past & $54(5.3)$ & $75(3.7)$ & $33(3.3)$ & \\
\hline Current & $326(32.3)$ & $602(29.8)$ & 338 (33.9) & \\
\hline \multicolumn{5}{|l|}{ Education $^{\dagger}(\mathrm{y})$} \\
\hline$\geq 15$ & $463(45.8)$ & 899 (44.5) & 404 (40.5) & 0.257 \\
\hline$\geq 12$ to $<15$ & 409 (40.5) & 867 (42.9) & 476 (47.7) & \\
\hline$<12$ & $140(13.7)$ & 255 (12.6) & $118(11.9)$ & \\
\hline \multicolumn{5}{|l|}{ House income $^{\dagger}$ ( 1,000 won) } \\
\hline$\geq 3,000$ & $356(35.2)$ & $651(32.2)$ & 395 (39.6) & 0.019 \\
\hline$\geq 1,000$ to $<3,000$ & $451(44.7)$ & $992(49.1)$ & 437 (43.8) & \\
\hline$<1,000$ & 203 (20.1) & 378 (18.7) & 166 (16.6) & \\
\hline
\end{tabular}

Values are presented as mean \pm SD or number (\%).

LTPA: leisure-time physical activity, Workact: work time physical activity.

*Analyzed by analysis of variance. ${ }^{\dagger}$ Analyzed by chi-square test (linear-by-linear association).

as for women, those in their $60 \mathrm{~s}$ showed a slight decrease. The hsCRP level increased with age in men and women, while the work time physical activities decreased with increasing age (Table 3 ).

\section{Relationship between Leisure Time Physical} Activity and Metabolic Syndrome

Adjustment for covariates to investigate the relationship 


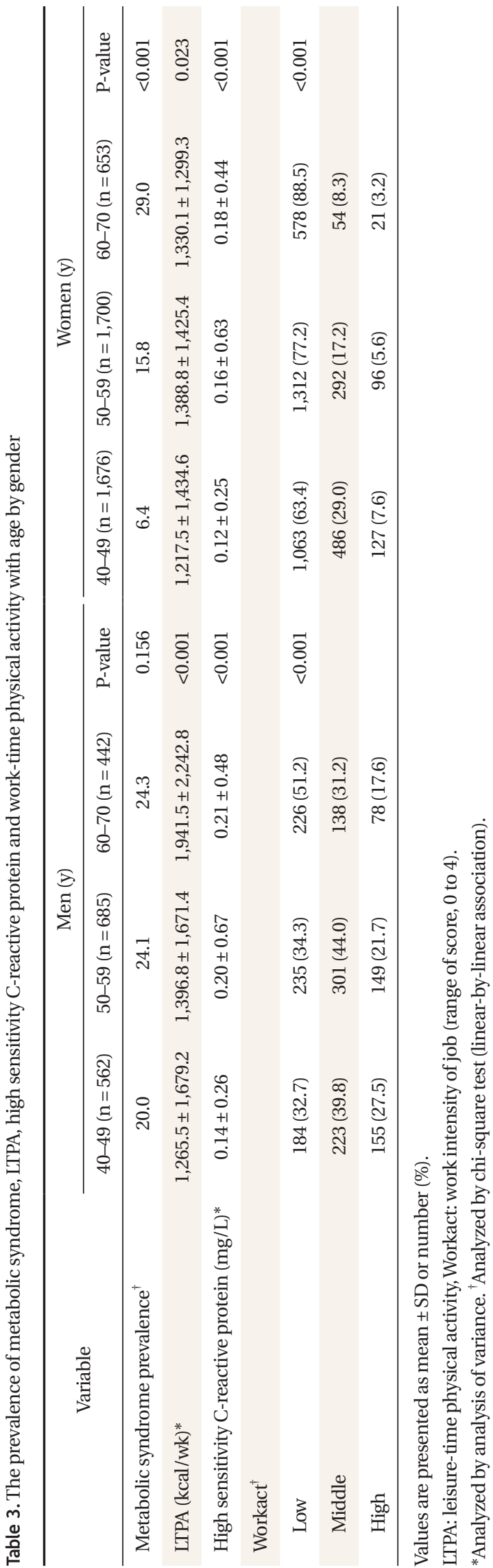

Table 4. ORs (95\% CIs) of LTPA with metabolic syndrome by logistic regression analysis

\begin{tabular}{cccccc}
\hline \multirow{2}{*}{ Variable } & \multicolumn{2}{c}{ Men } & & \multicolumn{2}{c}{ Women } \\
\cline { 2 - 3 } \cline { 5 - 6 } & OR $(95 \% \mathrm{CI})$ & P-trend & & OR (95\% CI) & P-trend \\
\hline LPTA & & & & \\
High & 1 & 0.146 & 1 & 0.036 \\
Middle & $1.00(0.72-1.80)$ & & $1.06(1.08-1.75)$ & \\
Low & $1.34(0.73-1.37)$ & & $1.54(0.87-1.34)$ & \\
\hline
\end{tabular}

Adjusted for age, smoking, alcohol intake, education, house income, and workact (menopause in women).

ORs: odds ratios, CIs: confidence intervals, LTPA: leisure-time physical activity.

between LTPA level and MS. ORs (CI) of MS were 1.0, 1.06 (1.08-1.75), and 1.54 (0.87-1.34) in low, middle, and high LTPA in women, respectively, which showed increased MS risk with a decrease in LTPA. In men, the results were 1.0, 1.00 (0.89-1.70), and 1.34 (0.73-1.37) in the low, middle, and high LTPA groups, respectively, but were not significant (Table 4).

\section{DISCUSSION}

In this study, the risk of MS increased with lower LTPA in women, but not in men. For the association between smoking, drinking and LTPA level, an inverse relationship was found between smoking and MS in men; and drinking, education level and MS in women.

Previous studies showed the effectiveness of physical activities for cardiovascular disease, especially in women, ${ }^{20,21)}$ and this study is also in line with such research. Recent meta-analyses, however, showed the effectiveness of physical activities in both men and women, despite the difference in the intensity of effectiveness (30\% in men and $40 \%$ in women) for cardiovascular disease. ${ }^{22)}$ When measuring physical activities, including work time physical activities and LTPA is ideal, but many studies use only LTPA due to the difficulty of measuring work time activity. ${ }^{17)}$

Effectiveness of LTPA for the prevention of cardiovascular disease has been reported in many studies. The Oslo study (a 28 year follow-up study of the local community) showed that in the middle or high LTPA group, the relative risk of MS was reduced to $0.65(0.54-0.80)$ and that of diabetes to $0.68(0.52-0.91)$ 
compared to the low LTPA group. ${ }^{23)}$ A study on physical activities in patients with impaired glucose tolerance showed that middle or high LTPA was effective for the prevention of cardiovascular and metabolic diseases. ${ }^{24)}$ A Finnish prospective study reported more reduction of MS incidence (in particular, FBS) in the middle or high LTPA group than in the low LTPA group even if there was no significant difference in the total energy consumption. ${ }^{25)}$ In a recent study, through the detailed measurement of physical activities $^{26)}$ and comprehensive physical activities across four areas (during work, home, transportation, and leisure time), it was found that work time physical activities and LTPA both are effective. $^{27)}$

Physical inactivity increases the incidence of chronic disease because optimization of energy consumption and insulin sensitivity is dependent on aerobic exercise. ${ }^{28)}$ When physical activity increased, the insulin resistance improved within a short time, and triglycerides and HDL cholesterol also gradually improved. ${ }^{29)}$ Although physical activity alone cannot explain the entire improvement in insulin resistance, it showed an independent influence on it even after other risk factors had been controlled. ${ }^{30)}$ Physical activity reduces chronic disease incidence via the improvement of low-level inflammation. Exercise changes the transmission of signals for insulin secretion regardless of whether there is weight change, which improves insulin tolerance and is also considered to reduce the production of hs-CRP, interleukin-6, interleukin-10, and tumor necrosis factors. ${ }^{31)}$ Apart from the direct improvement of insulin resistance, ${ }^{32,33)}$ physical activity also inhibits low-level inflammation. ${ }^{34,35)}$ According to NCEP ATP III, a lifestyle change, including increased physical activity, reduces the incidence of cardiovascular disease. Other studies involving cardiovascular disease patients also showed the effectiveness of physical activity on MS and insulin resistance. ${ }^{36)}$

This study measured LTPA quantitatively using a questionnaire. LTPA and MS showed a significant inverse relationship in women, but not in men. The difference in MS prevalence based on LTPA in men and women may have been due to the difference in various factors including loading factors (such as genetic, sex hormones, health behavior related culture), age, and work time physical activities. The prevalence of MS increased rapidly with age in women, but not in men. LTPA increased especially in after age 60 , and there was an inverse relationship between work time physical activities and LTPA.
The limitations of this study are as follows. First, as a crosssectional study, it could not explain the causality between LTPA and MS. Second, recall bias about LTPA could not be excluded and classification bias may have occurred. Third, measurement uncertainty of work time physical activities might have caused classification bias. Lastly, there was no data on diet, one of the most influential factors, and as such, the relationship between LTPA and MS might have been attenuated. Despite the limitations, however, one strength of this study is that the relationship between LTPA and MS was analyzed after correcting for medical history, health-related behaviors, and work time physical activities of the subjects, which may have reduced the possibility of confounding errors.

\section{CONFLICT OF INTEREST}

No potential conflict of interest relevant to this article was reported.

\section{REFERENCES}

1. Korea Centers for Disease Control and Prevention. The fourth national health and nutrition examination survey (KHANES V). Cheongwon: Korea Centers for Disease Control and Prevention; 2010.

2. Brouwer BG, Visseren FL, van der Graaf Y; SMART Study Group. The effect of leisure-time physical activity on the presence of metabolic syndrome in patients with manifest arterial disease. The SMART study. Am Heart J 2007;154: 1146-52.

3. US Department of Health and Human Resource. Physical activity and health: a report of the surgeon general. Atlanta (GA): US Department of Health and Human Services, Centers for Disease Control and Prevention, National Center Chronic Disease Prevention and health Promotion; 1996.

4. Kim J, Tanabe K, Yokoyama N, Zempo H, Kuno S. Association between physical activity and metabolic syndrome in middle-aged Japanese: a cross-sectional study. BMC Public Health 2011;11:624.

5. Reaven GM. Banting lecture 1988: role of insulin resistance 
in human disease. Diabetes 1988;37:1595-607.

6. Expert Panel on Detection, Evaluation, and Treatment of High Blood Cholesterol in Adults. Executive summary of the third report of the National Cholesterol Education Program (NCEP) Expert Panel on Detection, Evaluation, And Treatment of High Blood Cholesterol in Adults (Adult Treatment Panel III). JAMA 2001;285:2486-97.

7. Lakka TA, Laaksonen DE. Physical activity in prevention and treatment of the metabolic syndrome. Appl Physiol Nutr Metab 2007;32:76-88.

8. Orchard TJ, Temprosa M, Goldberg R, Haffner S, Ratner $\mathrm{R}$, Marcovina S, et al. The effect of metformin and intensive lifestyle intervention on the metabolic syndrome: the Diabetes Prevention Program randomized trial. Ann Intern Med 2005;142:611-9.

9. Carroll S, Cooke CB, Butterly RJ. Metabolic clustering, physical activity and fitness in nonsmoking, middle-aged men. Med Sci Sports Exerc 2000;32:2079-86.

10. Batty GD, Shipley MJ, Marmot M, Davey Smith G. Leisure time physical activity and coronary heart disease mortality in men symptomatic or asymptomatic for ischaemia: evidence from the Whitehall study. J Public Health Med 2003;25:1906.

11. Abaci A. Management of cardiovascular risk factors for primary prevention: evaluation of Turkey results of the EURIKA study. Turk Kardiyol Dern Ars 2012;40:135-42.

12. Kim DS, Koo HW, Kim DH, Bae JM, Shin MH, Lee MS, et al. A cohort study of physical activity and all cause mortality in middle-aged men in Seoul. Korean J Prev Med 1998;31:60415.

13. Kim JR, Nam BD, Kim JH, Lee SK, Moon JK, Lee JH, et al. Physical fitness, leisure time physical activity, and serum lipid levels in middle-aged male workers. Korean J Prev Med 1996; 29:173-86.

14. Rho YK, Yeh MH, Lee SK, Chun BY. Leisure time physical activity and its relationship to coronary risk factors in male workers. Korean J Prev Med 1993;26:332-46.

15. Korea Centers for Disease Control and Prevention. Indepth analysis of the Third National Health and Nutrition Survey: the health interview and health behavior survey part. Cheongwon: Korea Centers for Disease Control and Prevention; 2007.
16. Jeong YH, Seo YK, Lee JT, Koh SJ, Chae SM, Kim MH. Analysis of health department of Korean. Seoul: Korea Institute for Health and Social Affairs; 2006.

17. Cochrane T, Davey RC, Gidlow C, Smith GR, Fairburn J, Armitage CJ, et al. Small area and individual level predictors of physical activity in urban communities: a multi-level study in Stoke on Trent, England. Int J Environ Res Public Health 2009;6:654-77.

18. Kim DH. Effect of job and leisure time physical activity in the risk of colorectal cancer: a case-control study [dissertation]. Seoul: Seoul National University; 1997.

19. Alberti KG, Eckel RH, Grundy SM, Zimmet PZ, Cleeman JI, Donato KA, et al. Harmonizing the metabolic syndrome: a joint interim statement of the International Diabetes Federation Task Force on Epidemiology and Prevention; National Heart, Lung, and Blood Institute; American Heart Association; World Heart Federation; International Atherosclerosis Society; and International Association for the Study of Obesity. Circulation 2009;120:1640-5.

20. Rennie KL, McCarthy N, Yazdgerdi S, Marmot M, Brunner E. Association of the metabolic syndrome with both vigorous and moderate physical activity. Int J Epidemiol 2003;32:6006.

21. Yang X, Telama R, Hirvensalo M, Mattsson N, Viikari JS, Raitakari OT. The longitudinal effects of physical activity history on metabolic syndrome. Med Sci Sports Exerc 2008; 40:1424-31.

22. Shiroma EJ, Lee IM. Physical activity and cardiovascular health: lessons learned from epidemiological studies across age, gender, and race/ethnicity. Circulation 2010;122:74352.

23. Holme I, Tonstad S, Sogaard AJ, Larsen PG, Haheim LL. Leisure time physical activity in middle age predicts the metabolic syndrome in old age: results of a 28-year follow-up of men in the Oslo study. BMC Public Health 2007;7:154.

24. Pires MM, Salvador EP, Siqueira-Catania A, Folchetti LD, Cezaretto A, Ferreira SR. Assessment of leisure-time physical activity for the prediction of inflammatory status and cardiometabolic profile. J Sci Med Sport 2012;15:511-8.

25. Ilanne-Parikka P, Laaksonen DE, Eriksson JG, Lakka TA, Lindstr J, Peltonen M, et al. Leisure-time physical activity and the metabolic syndrome in the Finnish diabetes prevention 
study. Diabetes Care 2010;33:1610-7.

26. Hu G, Tuomilehto J, Borodulin K, Jousilahti P. The joint associations of occupational, commuting, and leisure-time physical activity, and the Framingham risk score on the 10year risk of coronary heart disease. Eur Heart J 2007;28:4928.

27. Chu AH, Moy FM. Associations of occupational, transportation, household and leisure-time physical activity patterns with metabolic risk factors among middle-aged adults in a middle-income country. Prev Med 2013;57 Suppl:S14-7.

28. Booth FW, Laye MJ, Lees SJ, Rector RS, Thyfault JP. Reduced physical activity and risk of chronic disease: the biology behind the consequences. Eur J Appl Physiol 2008;102:38190.

29. Durstine JL, Grandjean PW, Davis PG, Ferguson MA, Alderson NL, DuBose KD. Blood lipid and lipoprotein adaptations to exercise: a quantitative analysis. Sports Med 2001;31:1033-62.

30. Duncan GE, Perri MG, Theriaque DW, Hutson AD, Eckel RH, Stacpoole PW. Exercise training, without weight loss, increases insulin sensitivity and postheparin plasma lipase activity in previously sedentary adults. Diabetes Care 2003; 26:557-62.

31. Petersen AM, Pedersen BK. The anti-inflammatory effect of exercise. J Appl Physiol (1985) 2005;98:1154-62.

32. Zierath JR. Invited review: exercise training-induced changes in insulin signaling in skeletal muscle. J Appl Physiol (1985) 2002;93:773-81.

33. Kump DS, Booth FW. Alterations in insulin receptor signalling in the rat epitrochlearis muscle upon cessation of voluntary exercise. J Physiol 2005;562(Pt 3):829-38.

34. Lakka TA, Lakka HM, Rankinen T, Leon AS, Rao DC, Skinner JS, et al. Effect of exercise training on plasma levels of C-reactive protein in healthy adults: the HERITAGE Family Study. Eur Heart J 2005;26:2018-25.

35. Mokdad AH, Marks JS, Stroup DF, Gerberding JL. Actual causes of death in the United States, 2000. JAMA 2004;291: 1238-45.

36. Petersen KF, Dufour S, Savage DB, Bilz S, Solomon G, Yonemitsu $\mathrm{S}$, et al. The role of skeletal muscle insulin resistance in the pathogenesis of the metabolic syndrome. Proc Natl Acad Sci U S A 2007;104:12587-94. 